\title{
Study on the Influence of Rotational Speed and Pad Temperature of Pumped-Storage Set on Oil Mist Leakage of Thrust Bearing
}

Jie Sun

Hohai University

Yuquan Zhang ( $\nabla$ zhangyq@hhu.edu.cn )

Hohai University

Yuan Zheng

Hohai University

Xinfeng Ge

Hohai University

Yunlai Hong

Jiangxi Hongping Pumped Storage Co. Ltd.

E. Fernandez-Rodriguez

Technological Institute of Merida, Technological Avenue

\section{Research Article}

Keywords: pumped-storage set, thrust bearings, internal oil throwing, external oil throwing, air-oil-oil mist three-phase flow, evaporation and mass transfer process

Posted Date: December 16th, 2021

DOI: https://doi.org/10.21203/rs.3.rs-1154460/v1

License: (c) (i) This work is licensed under a Creative Commons Attribution 4.0 International License.

Read Full License 


\title{
Study on the influence of rotational speed and pad temperature of
}

\section{pumped-storage set on oil mist leakage of thrust bearing}

\author{
Jie Sun ${ }^{a}$, Yuquan Zhang ${ }^{b *}$, Yuan Zheng ${ }^{b}$, Xinfeng Ge ${ }^{b}$, Yunlai Hong ${ }^{c}$, E. Fernandez-Rodriguez ${ }^{\mathrm{d}}$ \\ a College of Water Conservancy and Hydropower Engineering, Hohai University, Nanjing 210098, China; \\ $b$ College of Energy and Electrical Engineering, Hohai University, Nanjing 210098, China; \\ c Jiangxi Hongping Pumped Storage Co. Ltd., Jingan, Jiangxi 330600, China; \\ d Technological Institute of Merida, Technological Avenue, Merida 97118, Mexico \\ *corresponding author: Yuquan Zhang (email: zhangyq@hhu.edu.cn)
}

\begin{abstract}
The accumulation of oil mist in the thrust bearings compromises the safety of the unit and prompts financial and environmental losses. To discuss the strategies for limiting its impact, the model uses the VOF approach to calculate the air-oil-oil mist three-phase flow, combined with the Lee model, to solve the evaporation and mass transfer process between the oil and oil mist. Our attention is drawn into the influence of unit speed and pad temperature, on the occurrence of external and internal leaks from the oil tank. A comparison of cases is made with five unit speeds $(100$ to $500 \mathrm{rpm})$ at constant temperature $\left(60^{\circ} \mathrm{C}\right)$, and with one unit speed $(500 \mathrm{rpm})$ at different temperatures $\left(56^{\circ} \mathrm{C}, 60^{\circ} \mathrm{C}, 62^{\circ} \mathrm{C}\right)$. With constant speed, the rise of pad temperature promotes the evaporation of the lubricating oil in an uneven manner, augmenting the occurrence of oil leaks. From findings, the increase of speed reduces the pressure change rate at the wall of the inner tank (external oil leaks) by $5.95 \%$, and of the oil slinger (internal leaks), by $44.64 \%$. The present results might help to suggest courses of action to reduce the oil mist leakage.
\end{abstract}

Key words: pumped-storage set; thrust bearings; internal oil throwing; external oil throwing; air-oil-oil mist three-phase flow; evaporation and mass transfer process

\section{Introduction}

Clean and renewable hydropower is crucial to sustainable society development. It may be regarded as safe and economical, and its dams can be used for irrigation and anti-flood strategies. But as a drawback, pollutants can be dispersed into the water due to the unavoidable leak of turbine oil and mist from the rotating components, such as thrust and shaft bearings. This is because the turbine oil, an essential lubricant derived from petroleum, atomizes with the presence of air at a particular temperature ${ }^{[1]}$. Over the last decades, several attempts have been made to understand and avoid this issue. Jung $\mathrm{K}$ et al. ${ }^{[2]}$ acknowledges the relationship between the centrifugal force and the oil leakage in the bearings, as well as between the deposition of oil mist and the high temperature caused by viscous shear strain of the oil film due to tremendous pressure ${ }^{[3]}$. The potential risk caused by oil mist leakage in hydropower stations is serious, as documented in several events. For instance, in the Cataract power station, the leak of lubricating oil augmented the temperature of the bearing, resulting in the unit shutdown ${ }^{[4]}$. During the operation of the Caijiazhou Hydropower Station, the water-lubricated guide bearing emitted a scratching sound due to collapse of oil slinger ring, hence discharging oil mist on the cover of the bearing ${ }^{[5]}$. In the Yantan Hydropower Station, the brake dust mixed with oil mist leak and contaminated the inner section of the 
generator, hence elevating the temperature of the stator ${ }^{[6]}$. The Tianwanhe Dafa hydropower station had a serious failure in the cover seal and the oil level of the thrust bearing tank declined $10 \mathrm{~mm} /$ day, forcing personnel to monitor and replenish the oil ${ }^{[7]}$. The Xiaolangdi Hydropower Station threw nearly $100 \mathrm{~L}$ of lubricating oil during the manual operation ${ }^{[8]}$. Since limiting the discharge of oil mist in the thrust bearing reduces the safety risk, the water pollution and biodiversity loss ${ }^{[9]}$, investigating its causes and consequences a continuing concern within scientists and engineers.

Solutions to the oil and oil mist leakage of hydropower stations exist from engineering practices but are specific to the actual operation of units. In addition, the methodology is limited in information and requires large human and economic resources. As a result, it is vital to understand the actual flow pattern inside the bearing oil tank and the causes of oil mist leakage in the system, in order to develop appropriate and reasonable solving schemes. However, this analytical solution is highly complex, and thus, may be approximated numerically using the finite difference method (FDM), finite element method (FEM), finite volume method (FVM), and spectral method ${ }^{[10]}$. Currently, many assessing studies of oil leaks and circulation patterns in bearings utilize industrial software ${ }^{[10]}$, such as Fluent, $\mathrm{CFX}^{[11]}$.

In recent years, with the development of numerical simulation technology, many high-performing bearing covers and structures have been put forward through studies of flow paths and possible occurrences of oil and oil mist leaks ${ }^{[12-14]}$. On the issue of oil mist accumulation, many scholars have mainly focused on the oil tank pressure and level. For example, Pang et al. ${ }^{[15]}$ studied the oil mist leak in the bearing from the flow field and temperature using the FDM, and the distribution of the oil, using the VOF two-phase flow and SST turbulence model. Chen et al. ${ }^{[16]}$ used a two-dimensional model to calculate the pressure distribution in the rotating oil basin of cylindrical guide bearings. An analysis was made between the lubricating oil viscosity and the generated oil level and pressure distribution. Deng et al. [17] dealt with the oil mist leakage of the hydro-generator bearing by optimizing the structure of the oil tank cover, based on flow theory analysis. In this case, the impeller's optimized scheme generated an oil-recovering pressure drop, reducing the oil mist rate from $4.9 \mathrm{~m}^{3} / \mathrm{h}$ to $0.36 \mathrm{~m}^{3} / \mathrm{h}$.

However, in the above research, scholars have only considered the oil-air two-phase flow in the tank, thus ignoring the discharge of oil mist. Because the mass transfer of the lubricating oil caused by the change of temperature and speed are central in the leakage production, a three-dimensional geometric multi-phase model, based on the Volume of Fluid (VOF), is used here to solve the air-oil-oil mist three-phase flow. The evaporation and condensation model is used to simulate the mass transfer between the oil and the oil mist. The main purpose of the paper is to determine anti-oil mist leakage measures for thrust bearings through two examinations: the produced oil flow pattern and discharge of oil mist in the oil bearing tank; the influence of unit speed and pad temperature on the cause of external and internal oil leak.

\section{Physical model and flow path of the oil tank}

\subsection{Physical model}

The thrust-bearing oil tank of a pumped-storage power is modelled in 3-dimensions. The thrust bearing is arranged on the top center of the upper frame, bearing the weight of the rotating parts and the axial thrust of the hydraulic unit. The thrust head and mirror plate are integrated and mounted on the shaft. The axial load is transmitted to the thrust bearing pad through the thrust head and the mirror plate. Each pad (12 total) is made of babbitt metal and supported by 18 elastic rubber pads underneath. A detachable, adjustable pad equalizes the level of the individual pads. Fig. 1 shows the assembly diagram of the thrust-bearing. The main components include the thrust head and mirror plate, the thrust bearing pad, the oil tank and cover, the elastic rubber and detachable pad, the upper frame, the oil slinger, and oil-retaining 
ring. Table 1 presents the main dimensions.
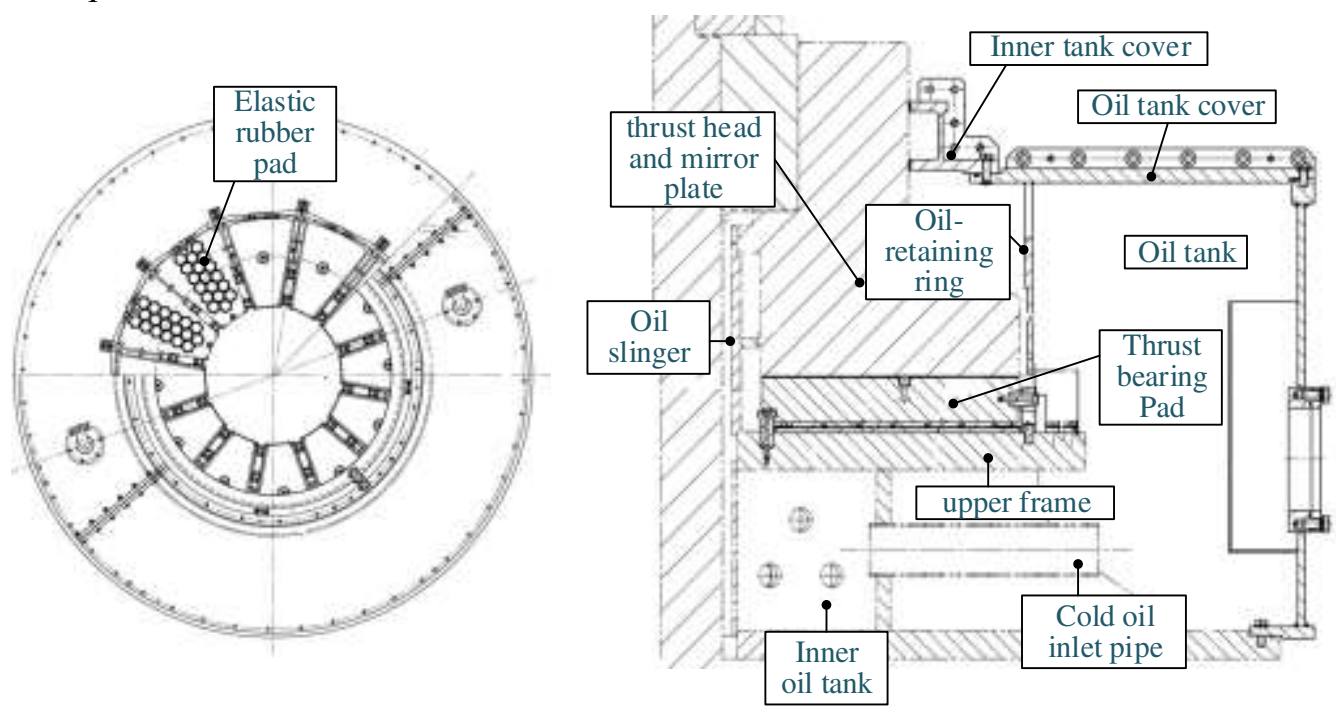

Fig.1 Assembly diagram of thrust bearing

Table 1 Main parameters of thrust bearings

\begin{tabular}{|c|c|c|c|c|c|c|c|}
\hline $\begin{array}{l}\text { Diameter } \\
\text { of thrust } \\
\text { bearing oil } \\
\text { tank } \\
\text { /mm }\end{array}$ & $\begin{array}{l}\text { The outer } \\
\text { diameter of } \\
\text { the thrust } \\
\text { bearing pad } \\
\quad / \mathrm{mm}\end{array}$ & $\begin{array}{c}\text { The inner } \\
\text { diameter of the } \\
\text { thrust bearing } \\
\text { pad } \\
/ \mathrm{mm}\end{array}$ & $\begin{array}{c}\text { number of } \\
\text { thrust } \\
\text { bearing pads }\end{array}$ & $\begin{array}{l}\text { Width } \times \\
\text { length } \\
\text { /mm }\end{array}$ & $\begin{array}{l}\text { Rated } \\
\text { speed } \\
/ \mathrm{r} / \mathrm{min}\end{array}$ & $\begin{array}{l}\text { Normal oil } \\
\text { level } \\
\text { /mm }\end{array}$ & $\begin{array}{c}\text { oil } \\
\text { grade }\end{array}$ \\
\hline 3300 & 2010 & 890 & 12 & $\begin{array}{c}560 \times \\
316\end{array}$ & 500 & 720 & $\begin{array}{c}\text { ISO } \\
\text { VG46 }\end{array}$ \\
\hline
\end{tabular}

Some components of the thrust bearing, considered unimportant for the three-dimensional model, are ignored to facilitate the mesh division and calculation. The whole and partial views of the model are shown in Fig.2.

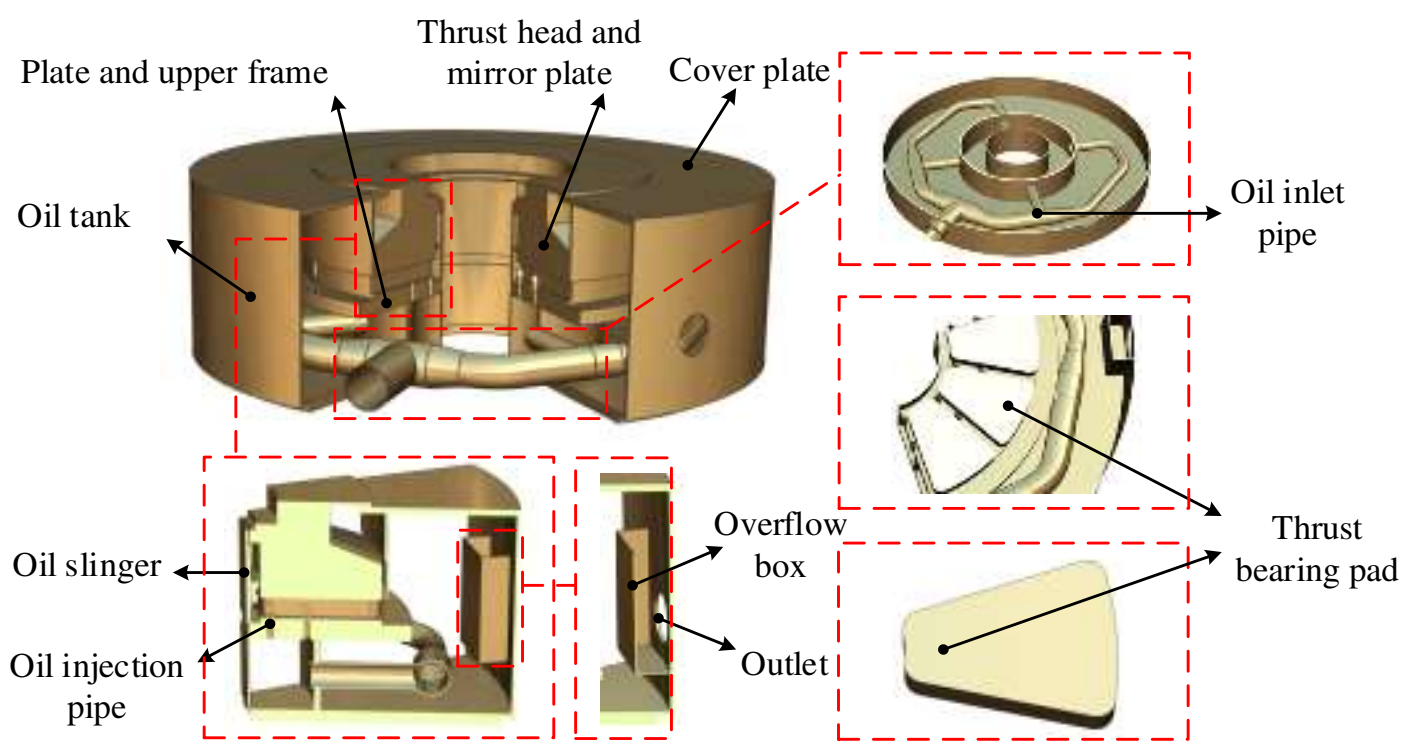

Fig.2 Simplified model of the thrust bearing oil tank

2.2 The circulating path of the lubricating oil in the oil tank

Cooling oil is supplied in a circulating cooling system, as shown in Figure 3 . The circulation loop 
mainly consists of a pump, inlet and outlet pipelines, connected to the oil tank ${ }^{[18]}$. The operation is decribed as follows. Initially, cold oil is pumped through the inlet pipe into the inner oil tank, where it is sprayed through the oil injection pipe to the bearing pad zone. The pressure from the wedge-shaped fluid film generated between the bearing pad and mirror plate, bears the gravity and axial force of the rotating parts. Therefore, if the pump is non-continuously operated, the pressure of the dynamic oil film becomes disturbed, rising the bearing temperature rapidly, threatening the unit's safety ${ }^{[19]}$. During the operation, the oil heats up due to viscous shear strain, and under the centrifugal force, it is ejected to the overflow box, before being discharged from the outlet pipe. The ejected oil is cooled outside the oil tank, before reentering in the inlet pipe, thus repeating the above process. The cooling efficiency of the system is high and unrestricted by the size of the thrust bearing.

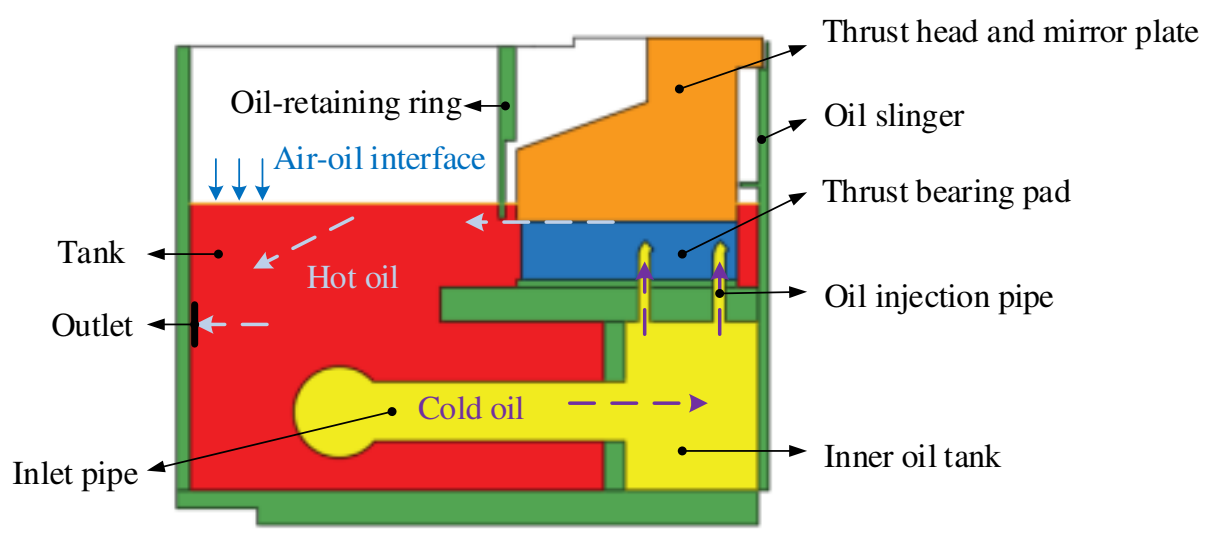

Fig.3 The circulating path of lubricating oil in the oil tank

\section{Numerical method}

3.1 Numerical calculation model and the governing equation

This paper uses the VOF model to calculate the air-oil-oil mist three-phase flow, in order to track and capture the interface of different phases. The relative velocity between the oil mist and the air is neglected, and the physical parameters of gas and liquid phases are assumed to be constant. Oil, air, and oil mist fail to permeate each other, and each phase shares a set of momentum and energy equations. The continuity equation is ${ }^{[20]}$

$$
\begin{gathered}
\nabla \cdot\left(\alpha_{A} \rho_{A} \underset{v}{v}\right)=-\frac{\partial}{\partial t}\left(\alpha_{A} \rho_{A}\right) \\
\nabla \cdot\left(\alpha_{L} \rho_{L} \stackrel{r}{v}\right)=-\frac{\partial}{\partial t}\left(\alpha_{L} \rho_{L}\right)+S_{a_{L}} \\
\nabla \cdot\left(\alpha_{V} \rho_{V} \stackrel{r}{v}\right)=-\frac{\partial}{\partial t}\left(\alpha_{V} \rho_{V}\right)+S_{a_{V}}
\end{gathered}
$$

where, $\alpha_{A} 、 \alpha_{L} 、 \alpha_{V}$ are the volume fractions of air, oil, and oil mist, respectively; $\rho_{A} 、 \rho_{L} 、 \rho_{V}$ are the density of air, oil, and oil mist; $\stackrel{\dot{v}}{v}$ is velocity; $S_{a_{L}}$ and $S_{a_{v}}$ are mass source terms for oil and oil mist to calculate mass transfer during evaporation and condensation. Furthermore, the sum of $\alpha_{A}, \alpha_{L}$ and $\alpha_{V}$ can be expressed as

$$
\alpha_{L}+\alpha_{A}+\alpha_{V}=1
$$

Since the three phases share the velocity field and energy field in the calculation process, both mixed 
density and velocity are adopted of the momentum equation and energy equation, as shown in equation (5)

- (6)

$$
\begin{gathered}
\rho=\alpha_{A} \rho_{A}+\alpha_{L} \rho_{L}+\alpha_{V} \rho_{V} \\
v=\frac{\alpha_{A} \rho_{A} v_{A}+\alpha_{L} \rho_{L} v_{L}+\alpha_{V} \rho_{V} v_{V}}{\rho}
\end{gathered}
$$

The momentum equation is ${ }^{[21]}$

$$
\frac{\partial}{\partial t}(\stackrel{\mathrm{r}}{v})+\nabla \cdot(\stackrel{\text { un }}{\rho v})=\rho g-\nabla p+\nabla \cdot\left[\mu\left(\nabla^{\mathrm{r}}+\nabla_{v}^{\mathrm{r}}{ }^{T}\right)\right]+\stackrel{\mathrm{r}}{F}
$$

Where, $p$ is pressure; $F$ is the interphase force; $\mu$ is dynamic viscosity; $g$ is the acceleration of gravity. The results are along the negative direction of Z-axis.

The energy equation is ${ }^{[21]}$

$$
\begin{gathered}
\frac{\partial}{\partial t}(\rho E)+\nabla \cdot[\mathrm{r}(\rho E+p)]=\nabla \cdot\left[k_{e f f} \nabla T\right]+S_{h} \\
E=\frac{\alpha_{A} \rho_{A} E_{A}+\alpha_{L} \rho_{L} E_{L}+\alpha_{V} \rho_{V} E_{V}}{\alpha_{A} \rho_{A}+\alpha_{L} \rho_{L}+\alpha_{V} \rho_{V}}
\end{gathered}
$$

Where, $E$ is energy; $k_{\text {eff }}$ is thermal conductivity coefficient; $T$ is the temperature; $S_{h}$ is the energy transfer during phase transition.

To close the RANS equations, the RNG $k-\varepsilon$ model is adopted. The existence of the oil film (the scale is micron) is ignored in the modeling process, so the flow scale span in the whole oil tank is somewhat important. Despite the standard model is often used for the multi-phase flow in the oil tank ${ }^{[17,22]}$, the RNG $k-\varepsilon$ model is used here due to the advantages for capturing the fluid rotation ${ }^{[23,24]}$. Namely, this model adapts to the swirling flow caused by shaft spinning and reflects substantially correct the streamline bending ${ }^{[25]}$. The transport equation of turbulent kinetic energy $k$ is expressed as

$$
\frac{\partial}{\partial t}(\rho k)+\frac{\partial}{\partial x_{i}}\left(\rho k u_{i}\right)=\frac{\partial}{\partial x_{j}}\left(a_{k} \mu_{e f f} \frac{\partial k}{\partial x_{j}}\right)+G_{k}+G_{b}-\rho \varepsilon_{k}
$$

Where, $G_{k}$ is the turbulent kinetic energy generated by laminar flow velocity gradient, calculated by equation (12)

$$
G_{k}=\mu_{t} S^{2}, \quad S=\sqrt{2 S_{i j} S_{i j}}
$$

Here the $S$ is the surface tension coefficient; $S_{i j}$ is the average tension; $\beta$ is the coefficient of thermal expansion; the coefficient $\eta_{0}=4.38, \beta=0.012$.

In Eq. 10 , the $G_{b}$ denotes the turbulence generated by buoyancy, calculated by equation (13)

$$
G_{b}=\beta g_{i} \frac{\mu_{t}}{\operatorname{Pr}_{\mathrm{t}}} \frac{\partial T}{\partial x_{i}}, \quad \beta=-\frac{1}{\rho}\left(\frac{\partial \rho}{\partial T}\right)_{p}
$$

Whilst the dissipation rate $(\varepsilon)$ equation is expressed as: 


$$
\frac{\partial}{\partial t}(\rho \varepsilon)+\frac{\partial}{\partial x_{i}}\left(\rho \varepsilon u_{i}\right)=\frac{\partial}{\partial x_{j}}\left(a_{\varepsilon} \mu_{e f f} \frac{\partial \varepsilon}{\partial x_{j}}\right)+C_{1 \varepsilon} \frac{\varepsilon}{k}\left(G_{k}+C_{3 \varepsilon} G_{b}\right)-C_{2 \varepsilon} \rho \frac{\varepsilon^{2}}{k}-R_{\varepsilon}
$$

The parameters $C_{1 \varepsilon}=1.42, C_{2 \varepsilon}=1.68, C_{3 \varepsilon}=\tanh |v / u|$ are constants, whereas $a_{k}$ and $a_{\varepsilon}$ are the turbulent Prandtl numbers of $k$ and $\varepsilon$ equations, $\alpha_{\mathrm{k}}=\alpha_{\varepsilon} \approx 1.393 . R_{\varepsilon}$ is an additional term to the $\varepsilon$ equation, calculated by Equation (14)

$$
R_{\varepsilon}=\frac{C_{\mu} \rho \eta^{3}\left(1-\eta / \eta_{0}\right)}{1+\beta \eta^{3}} \frac{\varepsilon^{2}}{k}
$$

During the oil heat-up process, oil vapor is formed, and the involved mass and energy transfer is simulated with the evaporation and condensation model. It is integrated with the popular Lee phase transformation model. The formula is: ${ }^{[26]}$

$$
\left\{\begin{array}{l}
S_{a L}=-r \cdot \alpha_{L} \rho_{L} \frac{T-T_{\mathrm{s}}}{T_{\mathrm{s}}}, \quad T . . T_{\mathrm{s}} \\
S_{a L}=r \cdot \alpha_{V} \rho_{V} \frac{T_{\mathrm{s}}-T}{T_{\mathrm{s}}}, \quad T<T_{\mathrm{s}} .
\end{array}\right.
$$

Where, $S_{a_{L}}$ is the mass source term of oil; $r$ is the mass transfer coefficient of phase transition; $T$ is the temperature of the oil; and $T_{\mathrm{s}}$ is the oil vapor saturation temperature.

\subsection{Computational domain}

Since 4 pipes compose the inlet and outlet structure of the thrust-bearing oil tank, a 1/4 symmetry condition is applied, and the number of meshes is reduced by setting periodic boundary surfaces. The calculation model is divided into the oil tank and pipe domains, as shown in Fig. 4 (a) and (b).

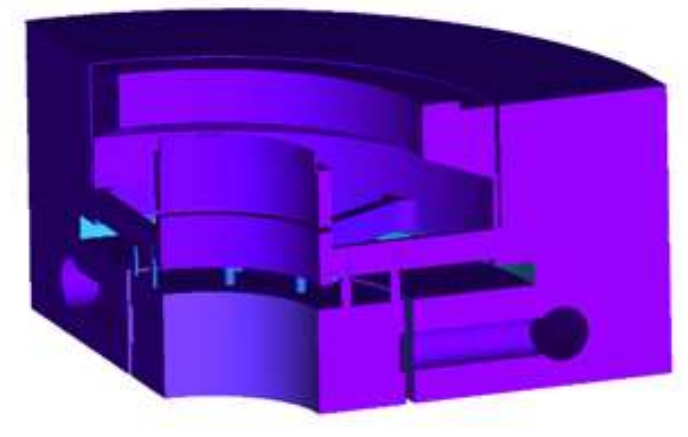

(a) oil tank domain

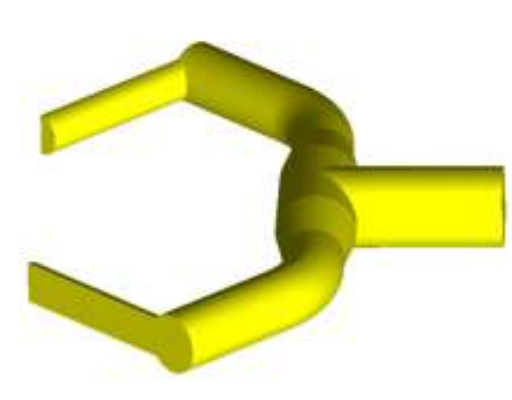

(b) oil pipe domain

Fig. 4 calculation domain

\subsection{Meshing}

The unstructured mesh with good adaptability is used to discretize the computational domain. Hence, the local mesh is refined in the oil slinger and injection pipe, and other small parts. The diagram of mesh division and local enlargement is shown in Fig. 5. 


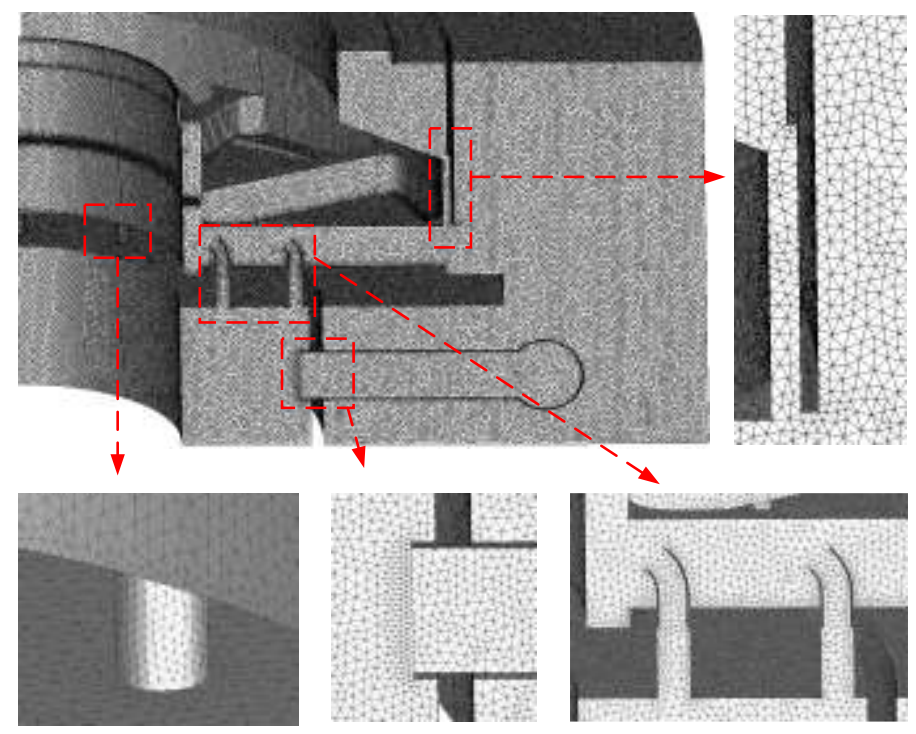

Fig. 5 diagram of computational domain mesh division and local mesh enlargement 3.4 Grid independence verification

A total of five sets of meshes are set for grid independence verification, as shown in Table 2. All cases use the same inlet and boundary conditions. A comparison is subsequently made using the steady point temperature and velocity, near the thrust head above the oil tank (see Table 3).

Table 2 Mesh cases

\begin{tabular}{cccccc}
\hline & Mesh 1 & Mesh 2 & Mesh 3 & Mesh 4 & Mesh 5 \\
\hline oil tank cells & 1399178 & 2481616 & 3567925 & 4982611 & 6208638 \\
oil pipe cells & 398277 & 626555 & 875634 & 1072185 & 2071980 \\
total cells & 1797455 & 3108171 & 4443559 & 6054796 & 8280618 \\
\hline
\end{tabular}

Table 3 The changes of pressure, temperature, and velocity at a point in the domain

\begin{tabular}{ccccccc}
\hline case & $\begin{array}{c}\text { pressure } \\
(\mathrm{Pa})\end{array}$ & $\begin{array}{c}\text { temperature } \\
\left({ }^{\circ} \mathrm{C}\right)\end{array}$ & $\begin{array}{c}\text { velocity } \\
\left(\mathrm{m} / \mathrm{s}^{-1}\right)\end{array}$ & $\begin{array}{c}\text { The error of } \\
\text { pressure } \\
(\%)\end{array}$ & $\begin{array}{c}\text { The error of } \\
\text { temperature } \\
(\%)\end{array}$ & $\begin{array}{c}\text { The error of } \\
\text { velocity }(\%)\end{array}$ \\
\hline M1 & -24926.5 & 311.64 & 18.68 & $/$ & $/$ & $/$ \\
M2 & -23675.9 & 312.33 & 19.13 & 5.01715 & 0.221409 & 2.408994 \\
M3 & -23019.7 & 312.86 & 19.48 & 2.77159 & 0.169692 & 1.829587 \\
M4 & -22812.3 & 313.13 & 19.63 & 0.90097 & 0.086301 & 0.770021 \\
M5 & -22661.1 & 313.21 & 19.65 & 0.6628 & 0.025548 & 0.101885 \\
\hline
\end{tabular}

By combining results from Table 3 and Fig. 6 (a), it can be seen how the temperature, pressure, and velocity initially increase but then asymptote with the number of cells. After 6 million cells (M4 case), the error is $<1 \%$. Its air-oil interface is substantially precise and stable, compared with predictions using less than 3 million (M2 case), as shown in Fig. 6 (b). The M4 case is hence used, based on the computing cost and accuracy of results. 


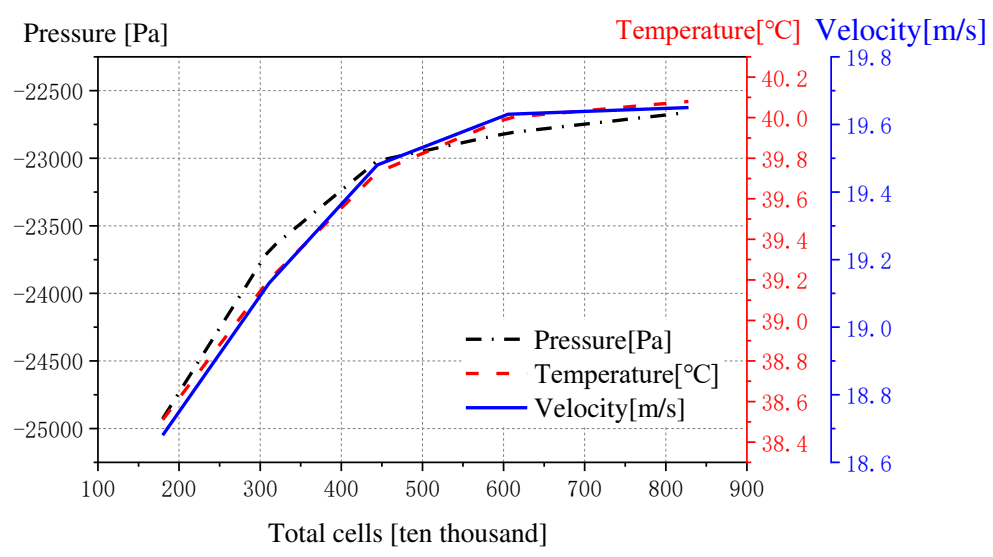

(a) The curve of temperature, pressure, and flow velocity at a certain point in the oil tank with the number of cells
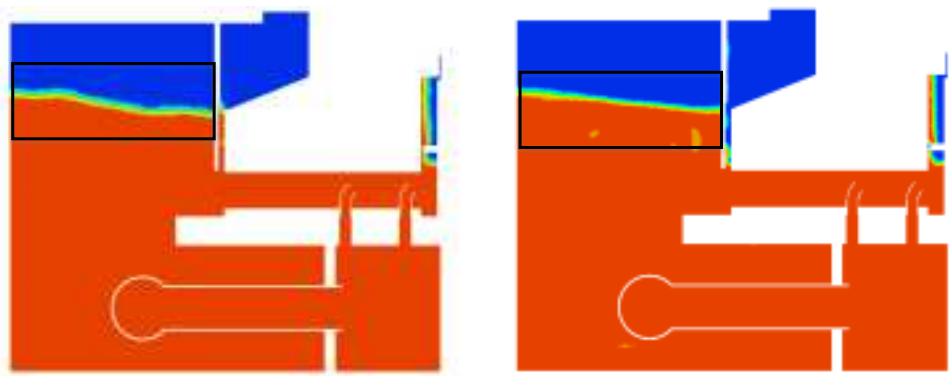

(b) Diagrams of air-oil interfaces for M2 and M4

Fig. 6 Grid independence verification

\subsection{Condition}

Fig. 7 shows the monthly averaged temperature of the 12 thrust-bearing pads from January to May 2021. As seen, the average (standard deviation) temperature of all bearing pads is $58.76^{\circ}( \pm 0.54)$, a stable trend across the year.

To understand the influence of operating parameters on the leak propensity, a comparison of working conditions is made with unit speed augmentation $(100$ to $500 \mathrm{rpm})$ at a specific $\left(60^{\circ} \mathrm{C}\right)$ temperature, and with rated speed $(500 \mathrm{rpm})$, at above $\left(56^{\circ} \mathrm{C}\right)$ and below $\left(62^{\circ} \mathrm{C}\right)$ the specific temperature. Table 4 summarizes the operating conditions.

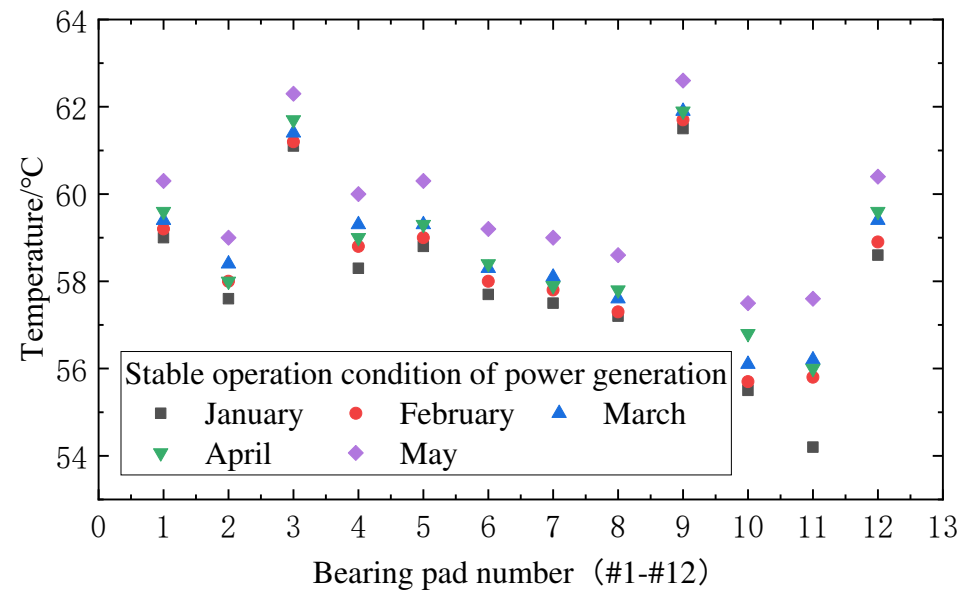

Fig. 7 Monthly average temperature diagram of bearing pad \#1 to \#12 under the stable operation of power generation 
Table 4 Calculation parameters of stable operating conditions

\begin{tabular}{cccc}
\hline Case & Operating conditions & $\begin{array}{c}\text { Speed } \\
/ \mathrm{r} / \mathrm{min}\end{array}$ & $\begin{array}{c}\text { Bearing pad } \\
\text { temperature } /{ }^{\circ} \mathrm{C}\end{array}$ \\
\hline 1 & 500 & 56 \\
2 & 500 & 60 \\
3 & power generation & 500 & 62 \\
4 & & 100 & 60 \\
5 & & 200 & 60 \\
6 & 300 & 60 \\
7 & & 400 & 60 \\
\hline
\end{tabular}

\subsection{Numerical solution method and boundary conditions}

The solver based on pressure is selected to run the calculations. The VOF model is employed to calculate the air-oil-oil vapor three-phase flow to capture the interface between different phases. The implicit algorithm balances the pressure gradient and the volume force in the momentum equation. Whilst the implicit volume force improves the convergence of the solution and the Lee model calculates the evaporation and mass transfer process between the oil and oil vapor. The mirror plate and thrust head are set as the rotating wall. The rotating speed is set as the unit speed under the current case, and the other walls are set as the static wall. The RNG $k-\varepsilon$ model closes the RANS equations. The coupled algorithm solves the pressure-velocity coupling and the discrete scheme with second-order precision, with the pseudo transient flow. The time scale is 0.5 .

In terms of operation, the discharge of thrust-bearing oil is about $3500 \mathrm{~L} / \mathrm{min}$, the outlet pressure of the oil pump is $0.4 \mathrm{Mpa}$, and the inlet pressure of the oil tank is $0.25-0.3 \mathrm{Mpa}$. The hot oil is ejected through the overflow box at atmospheric pressure. The oil temperature in the tank is about $40^{\circ} \mathrm{C}$ and vaporizes at $45^{\circ} \mathrm{C}$ [27], thus forming oil mist. As shown in Fig. 7 the temperatures of the thrust-bearing pads are slightly different. In this paper, all pad temperatures under the same case are assumed to be the same, and the influence of wedge clearance and the thrust oil film is ignored in the calculation process. The specific boundary and initialization conditions are as follows:

(a) Inlet: The inlet mass flow is $12.54 \mathrm{~kg} / \mathrm{s}$. The inlet pipe has a cold oil temperature of $35^{\circ} \mathrm{C}^{[28]}$, a turbulent intensity of $5 \%$, and a hydraulic diameter of $219 \mathrm{~mm}$.

(b) Outlet: The hot oil initially flows into the overflow box and then to the outlet pipe, with null relative pressure.

(c) Walls: the thrust head and mirror plate are set as rotating walls. According to Table 4, the speed is 100-500 $\mathrm{r} / \mathrm{min}$. The remaining walls are static without slip.

(d) Temperature setting: The initial temperature of the oil in the oil tank is $40^{\circ} \mathrm{C}$. The temperature of the inlet pipe is $35^{\circ} \mathrm{C}$, and the bearing pad temperature varies from $56^{\circ} \mathrm{C}$ to $62^{\circ} \mathrm{C}$ according to the case.

(e) Oil setting: The oil level is initially at $720 \mathrm{~mm}, 20 \mathrm{~mm}$ higher than the overflow box.

(f) Calculation: The reference point is at the mid inlet section, with a pressure of $0.3 \mathrm{Mpa}$.

These boundary conditions are illustrated in Fig. 8. 


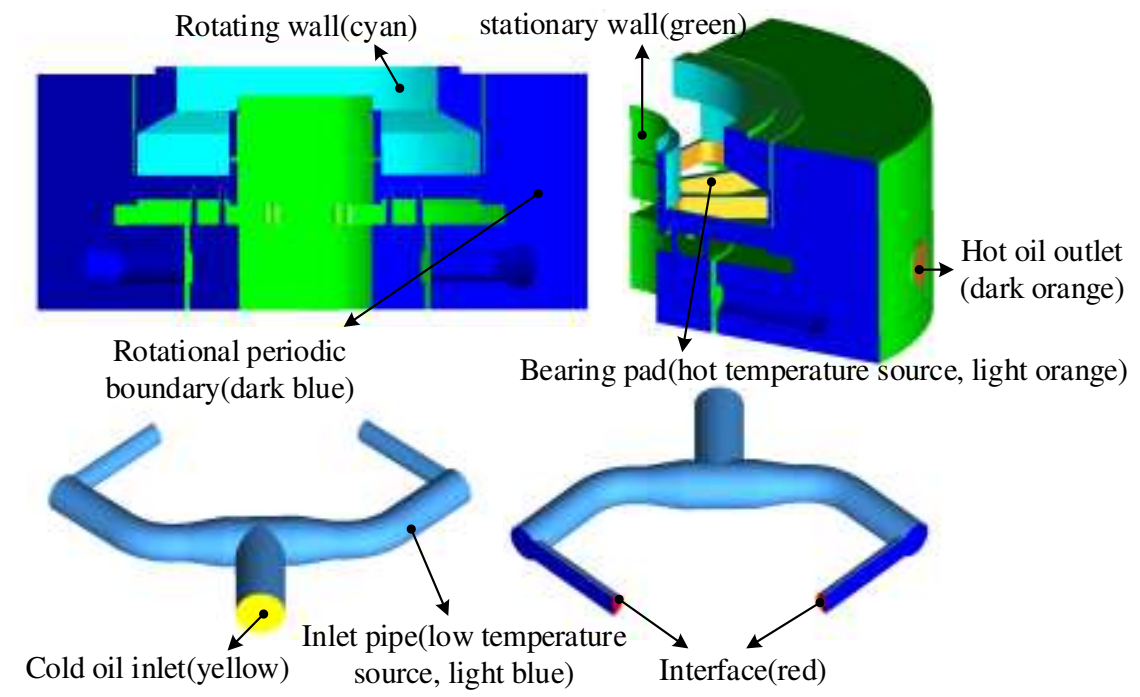

Fig. 8 Boundary condition

\section{Results and Discussion}

4.1 Influence of temperature change on flow characteristics in the oil tank

An implication of the temperature change in the bearing pad under maximum speed relates to the amount of oil evaporation, affecting the oil level and mist formation. The following two aspects are discussed in sections 4.1.1 and 4.1.2.

4.1.1 Influence of temperature change on the oil level

The influence of temperature is analyzed in the produced air-oil interface on periodic boundary surface, region A in Fig. 9 (b). As seen, the oil level in the periodic boundary surface decreases parabolically from the outer wall to the oil-retaining ring due to increase of temperature and of evaporation as well. This level shape is due to influence of the centrifugal force of the thrust head and the mirror plate. The curve for the highest pad temperature with transverse distance shows a larger oil drop, compared with the other two, at $\mathrm{Y}>-1.45$. However, the rate of transverse oil level decline with pad temperature is unclear near the outer wall and similar for $\mathrm{Y}>-1.2$ and temperatures lower than $62^{\circ} \mathrm{C}$. Thus, the trend is specific to position: 0.79 for $62^{\circ} \mathrm{C}$ and 0.785 for $60^{\circ} \mathrm{C}$ near the outer wall; 0.767 for $60^{\circ} \mathrm{C}$ and 0.751 for $62^{\circ} \mathrm{C}$ near the oil-retaining ring. This is exemplified in Fig. 9 (a).

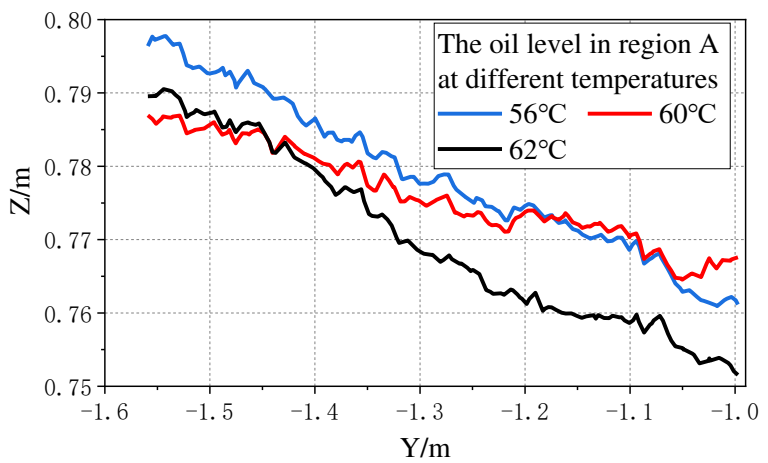

(a)

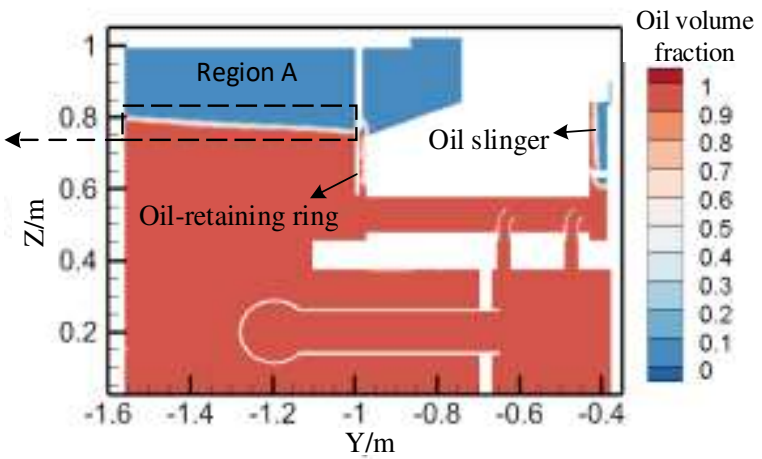

(b)

Fig. 9 Curve of oil level change in region A at different pad temperatures

4.1.2 Influence of temperature change on oil mist formation

The temperature not only affects the oil level but also the formation and distribution of the oil mist.

From results (Fig. 10), the volume fraction distribution of oil mist increases with pad temperature and 
accumulates in two regions: 1) between the thrust head and the oil-retaining ring; 2) within the oil slinger due to atomization of the oil as result of oil rotation and deflection from the seal. The top of the first zone contains the oil cover seal, where the oil mist gathers and spreads, causing external leak due to the pressure difference. Whereas the top of the second zone is connected with the atmosphere. Once the oil mist bypasses the deflection caused by the oil slinger, it can escape due to low pressure (caused by the rotation of the rotor), leading to internal oil leak.

In the context of distribution, the oil mist climbs up along the thrust head slope, and gathers between the thrust head and the oil-retaining ring. Likewise, the oil mist accumulates more significantly below the propelled oil zone with the pad temperature (Fig. 10).

Under the current temperature range $\left(54.2^{\circ} \mathrm{C}-62.6^{\circ} \mathrm{C}\right)$, the oil mist is retained from the action of the oil slinger. However, the operation increases the oil mist accumulation and pressure difference between the inside and outside of the oil tank. Due to the dynamic and static clearance, a small gap in the sealing tooth is inevitable, and oil leak ensues.

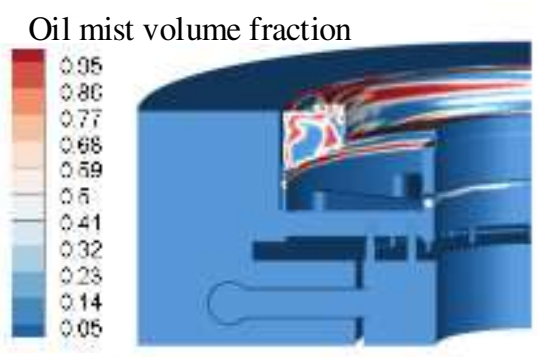

(a) $\mathrm{T}=56^{\circ} \mathrm{C}$

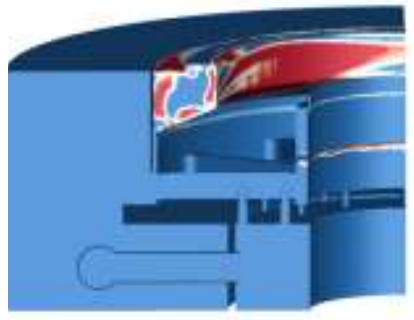

(b) $\mathrm{T}=60^{\circ} \mathrm{C}$

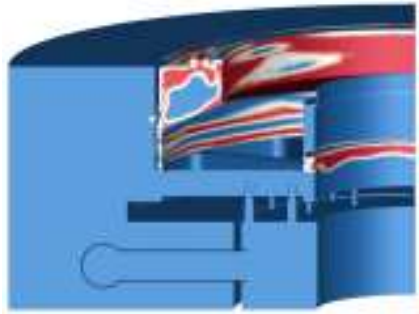

(c) $\mathrm{T}=62^{\circ} \mathrm{C}$

Fig. 10 Diagrams of volume fraction distribution of oil mist in oil tank at different pad temperatures 4.2 Influence of speed change on flow characteristics in the oil tank

Following the reason of Jung K, et al. ${ }^{[2]}$, the oil and mist leakage is related, besides temperature, to the unit speed. The following discuss the influence of unit speed variation (temperature of $60^{\circ} \mathrm{C}$ ) on the lubricating oil level and mist generation, and temperature and velocity of the oil tank.

\subsubsection{Influence of speed change on the oil level}

Fig. 11 shows the enlarged cloud diagram of oil volume fraction at different speeds at periodic boundary surfaces: around the oil slinger (region B) and the oil-retaining ring.

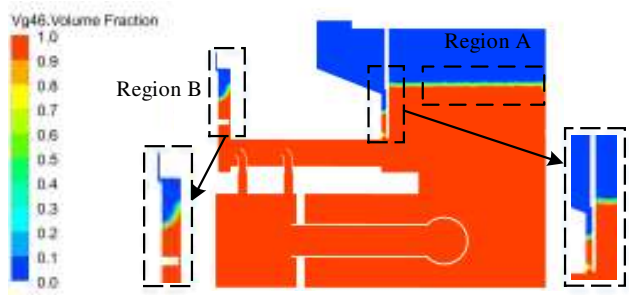

(a) $100 \mathrm{r} / \mathrm{min}$

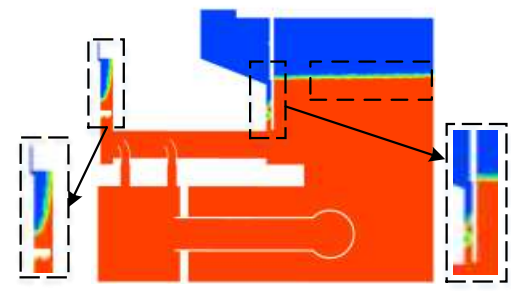

(b) $200 \mathrm{r} / \mathrm{min}$

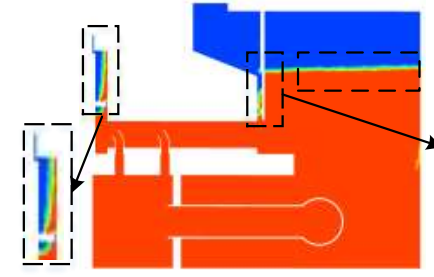

(c) $300 \mathrm{r} / \mathrm{min}$

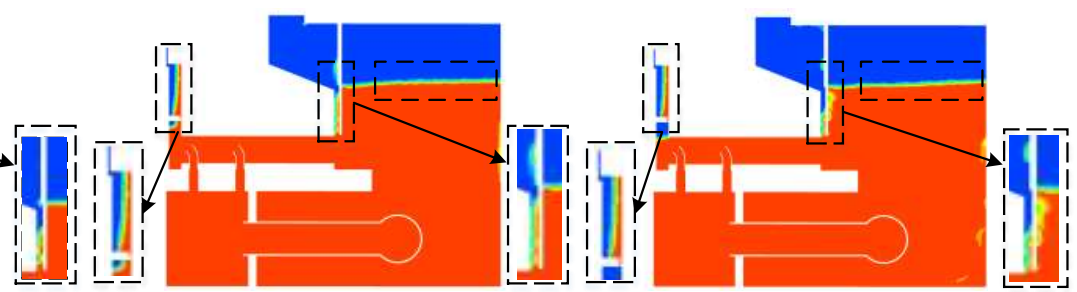

(d) $400 \mathrm{r} / \mathrm{min}$ (e) $500 \mathrm{r} / \mathrm{min}$

Fig. 11 Cloud diagram of oil volume fraction distribution on periodic boundary surface at different speeds 
As seen, the lubricating oil begins to "climb" along the wall of the oil slinger with speed. However, the unit speed affects little the mist formation around the oil retaining ring, although some differences can be observed below the outer tank. To clarify things, Figure 12 shows the oil level with transverse distance for the regions around the oil slinger and below the outer tank.. Distinctively, the slope of the oil level around the oil slinger rises with speed, in line with mist observations, and the level tends to converge at $\mathrm{Y}=-0.42$ regardless of the speed. The inclination and level difference of the curves may be described appropriately $\left(\mathrm{R}^{2}>0.99\right)$ with a quadratic fitted function. This quadratic coefficient provides a measure of the opening size of the parabola. It increases from 25.9 to 1104.2 with the unit speed.

For region $\mathrm{A}$, the oil level decreases from the outer wall to oil retaining ring in some extent with speed. For instance, the lowest speed case exhibits an almost constant highest level with transverse distance, however, the oil level curves with remaining speeds is interconnected, particularly near the outer wall. To capture the complexities of the phenomenon, Fig. 13 summarizes the statistics of the oil level. With speed augmentation, the overall fluctuation and drop of level around the oil retaining ring increases. The highest level near the outer wall remains almost unchanged.

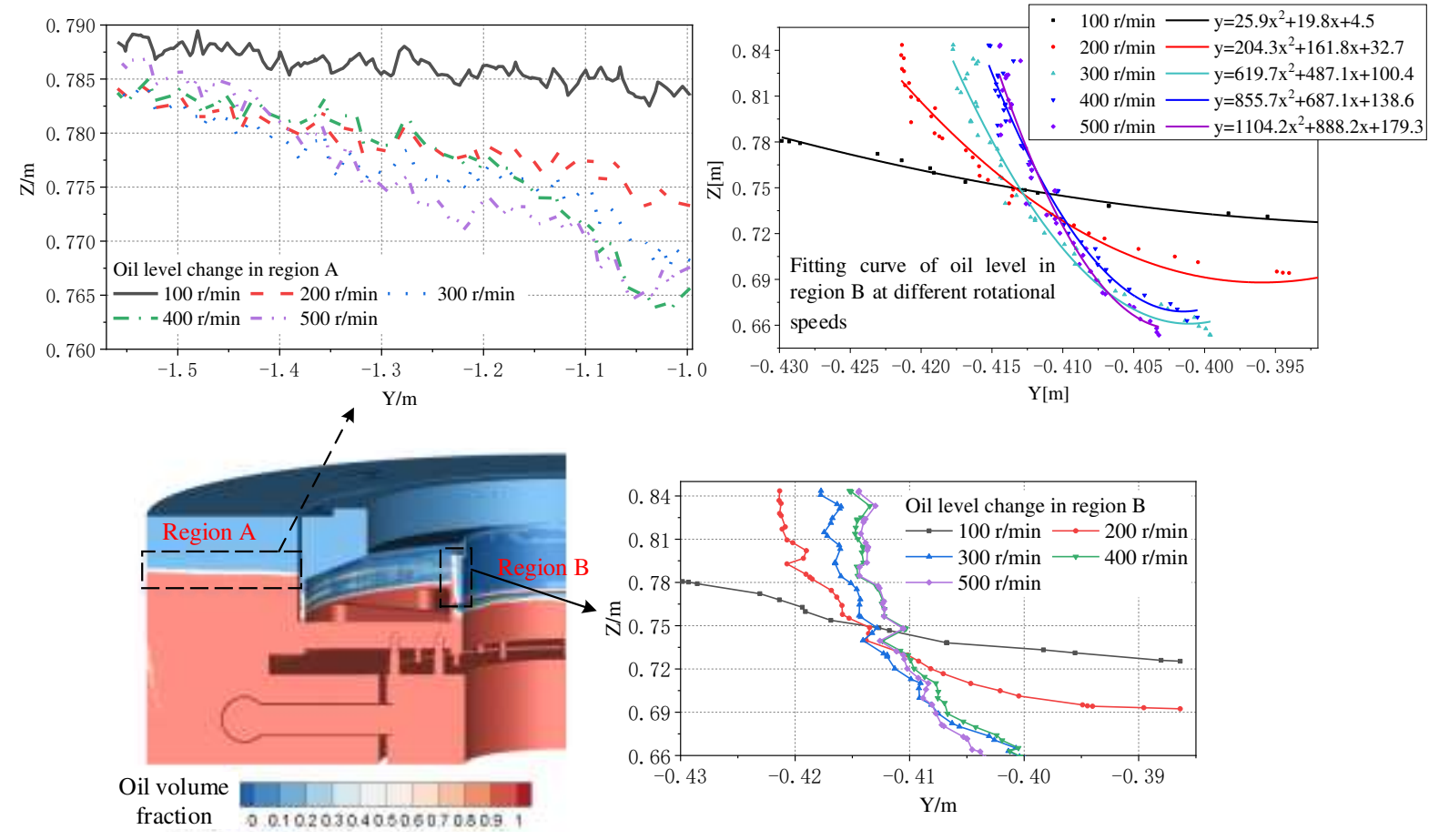

Fig. 12 Oil level curves of region A and region B at different speeds

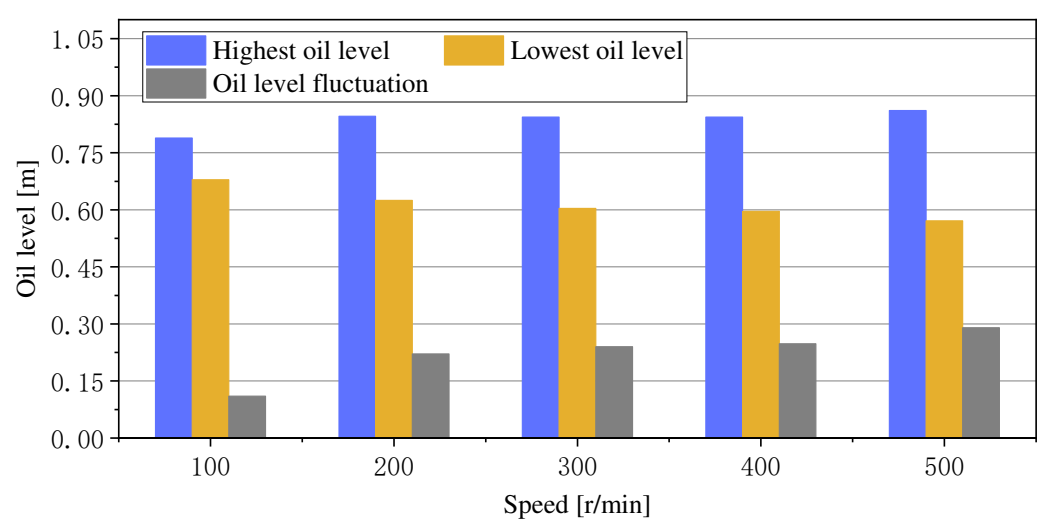

Fig. 13 Bar chart of oil variation in region A at different rotation speeds

This interesting result can be explained by the increase of Reynolds number in region B, 
$\operatorname{Re}=\rho v d / \mu$. where $\rho$ is the density, $v$ is the velocity, $d$ is the hydraulic diameter, and $\mu$ is the viscosity. Since turbulence occurs for values $>2300$, the oil agitates and its surface rises, leading to a larger contact area between the oil and air, aggravating the atomization of lubricating oil. This conclusion is consistent with Feng et al. ${ }^{[29]}$. In addition, Liu et al. ${ }^{[30]}$ believe an eccentricity between the thrust head and the oil slinger causes an uneven oil ring, leading to eccentric effect on pump performance. This in turn exacerbates the oil channeling and augments the probability of internal oil leak.

\subsubsection{Effect of rotational speed change on oil mist formation}

The influence of speed on oil mist is studied in terms of oil vapor volume fraction at the three periodic boundary surfaces: Region A, around the oil slinger; Region B, between the thrust head and oil-retaining ring; Region C, below the outer oil tank cover. It is illustrated in Fig. 14. For the region A, the oil mist accumulation below the deflected (oil) zone appears and augments with speeds greater than $300 \mathrm{rpm}$. A close examination of Fig. 14 (local diagrams) reveals the oil still remains along with the oil slinger, thus, the propelling of oil, away from the seal, becomes an efficient anti-oil throwing process .

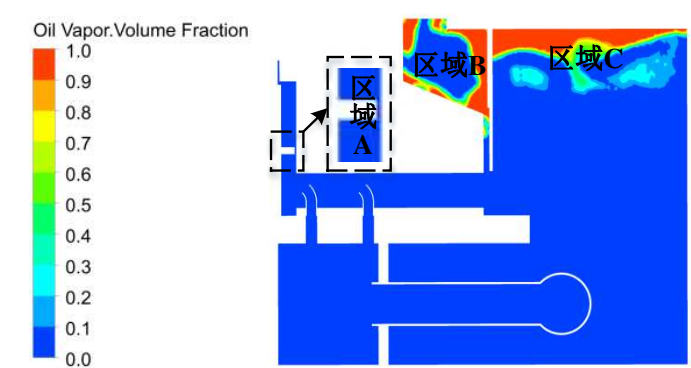

(a) $100 \mathrm{r} / \mathrm{min}$

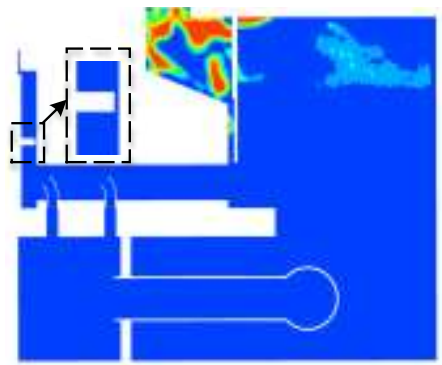

(b) $200 \mathrm{r} / \mathrm{min}$

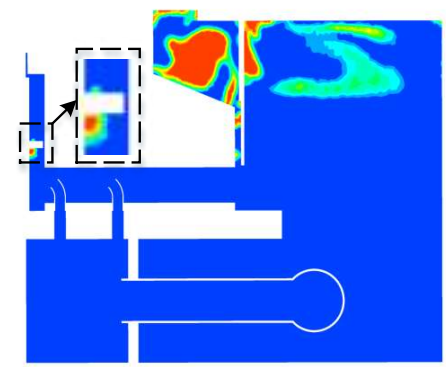

(c) $300 \mathrm{r} / \mathrm{min}$

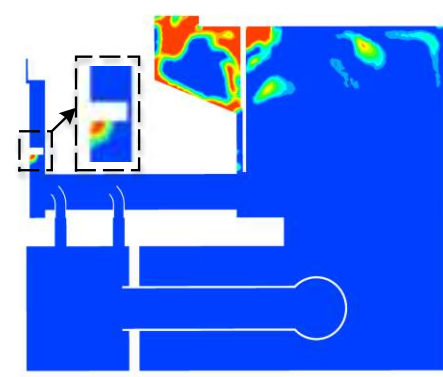

(d) $400 \mathrm{r} / \mathrm{min}$

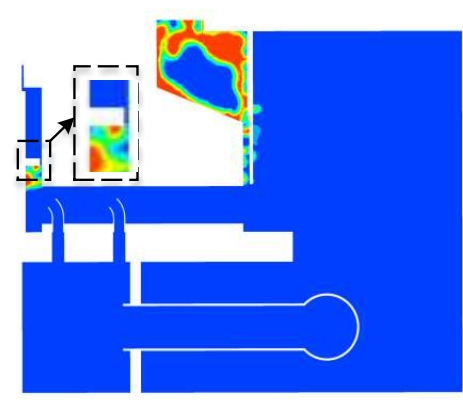

(e) $500 \mathrm{r} / \mathrm{min}$

Fig. 14 Cloud diagram of oil mist volume fraction of the periodic boundary surface at different speeds

By contrast, oil mist in Region $\mathrm{C}$ rises to the oil tank near the oil-retaining ring and lowers and disappears towards the region $\mathrm{B}$ with speed. In region $\mathrm{B}$, the oil mist climbs and tends to adhere to the walls of the inner tank homogenously for $\mathrm{n}=100,400,500 \mathrm{rpm}$ but not for $\mathrm{n}=200 \mathrm{rpm}$ due to small remnants in region C. Contrastingly, the oil mist in $n=300 \mathrm{rpm}$ accumulates in the middle of the inner tank cover due to significant remnants in Region C. The Region C's static seal parts always prevent leakage and are ignored in our analysis.

\subsubsection{Influence of rotating speed change on oil tank pressure}

Because oil mist accumulation and leakage are or not sequenced, depending on the sealing performance, scholars examine the sealing effectiveness such as the seal teeth and thrust head (static and dynamic parts) through the top tank's pressure distribution ${ }^{[15-17,22]}$. Furthermore, the pressure distribution in the oil tank has a specific influence on the distribution of oil mist.

Fig. 15 shows the mixed-phase pressure distribution of the periodic boundary surfaces at different 
speeds. Precisely, the highest pressure zone is located around cold oil inlet pipe, followed by the inner oil tank. The pressure of the system tends to decrease, as the cold oil enters the thrust bearing pad, thus the lowest pressure zone is above the oil tank. The pressure around the oil slinger decreases with speed, thus increases oil mist accumulation. To further study the leakage occurrence, the pressure distributions on the walls near the inner tank cover (curve A) and oil slinger (curve B) are plotted, as shown in Fig. 16.

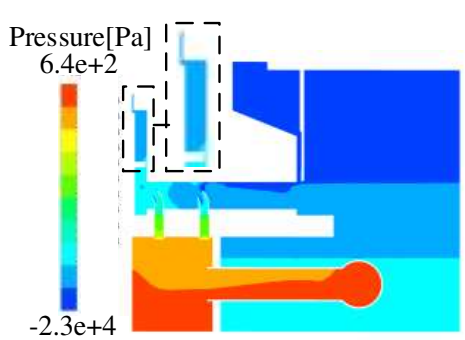

(a) $100 \mathrm{r} / \mathrm{min}$

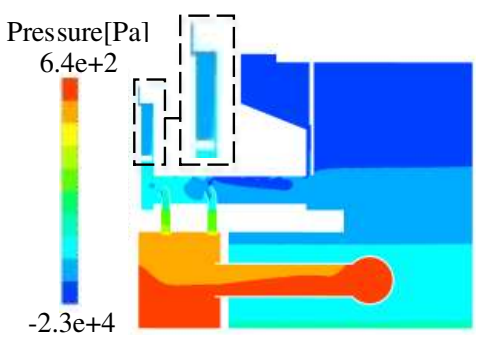

(b) $200 \mathrm{r} / \mathrm{min}$

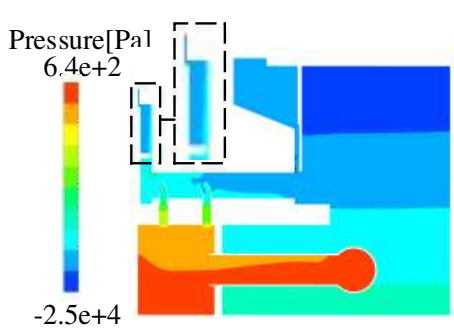

(c) $300 \mathrm{r} / \mathrm{min}$

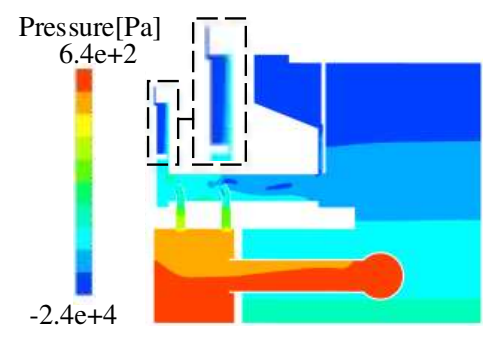

(d) $400 \mathrm{r} / \mathrm{min}$

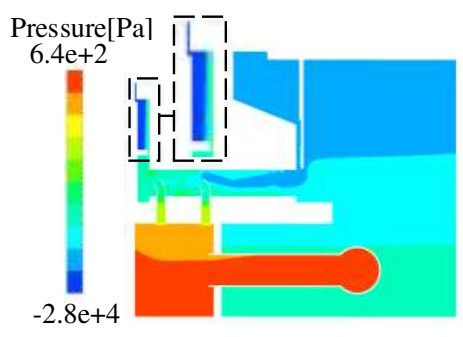

(e) $500 \mathrm{r} / \mathrm{min}$

Fig. 15 pressure distribution cloud diagram of mixed-phase on the rotating periodic boundary surface at different speeds

Plainly, the pressure curves in each region are almost constant and decrease with speed but at different rate: $5.95 \%$ for curve A and $44.64 \%$ for B. Taken together with the low-pressure zone around the oil slinger (curve B), the increase of speed will reduce the pressure at the oil mist aggregation region and aggravate the leakage. As a result, the speed augmentation prompts more the internal rather than external leak.
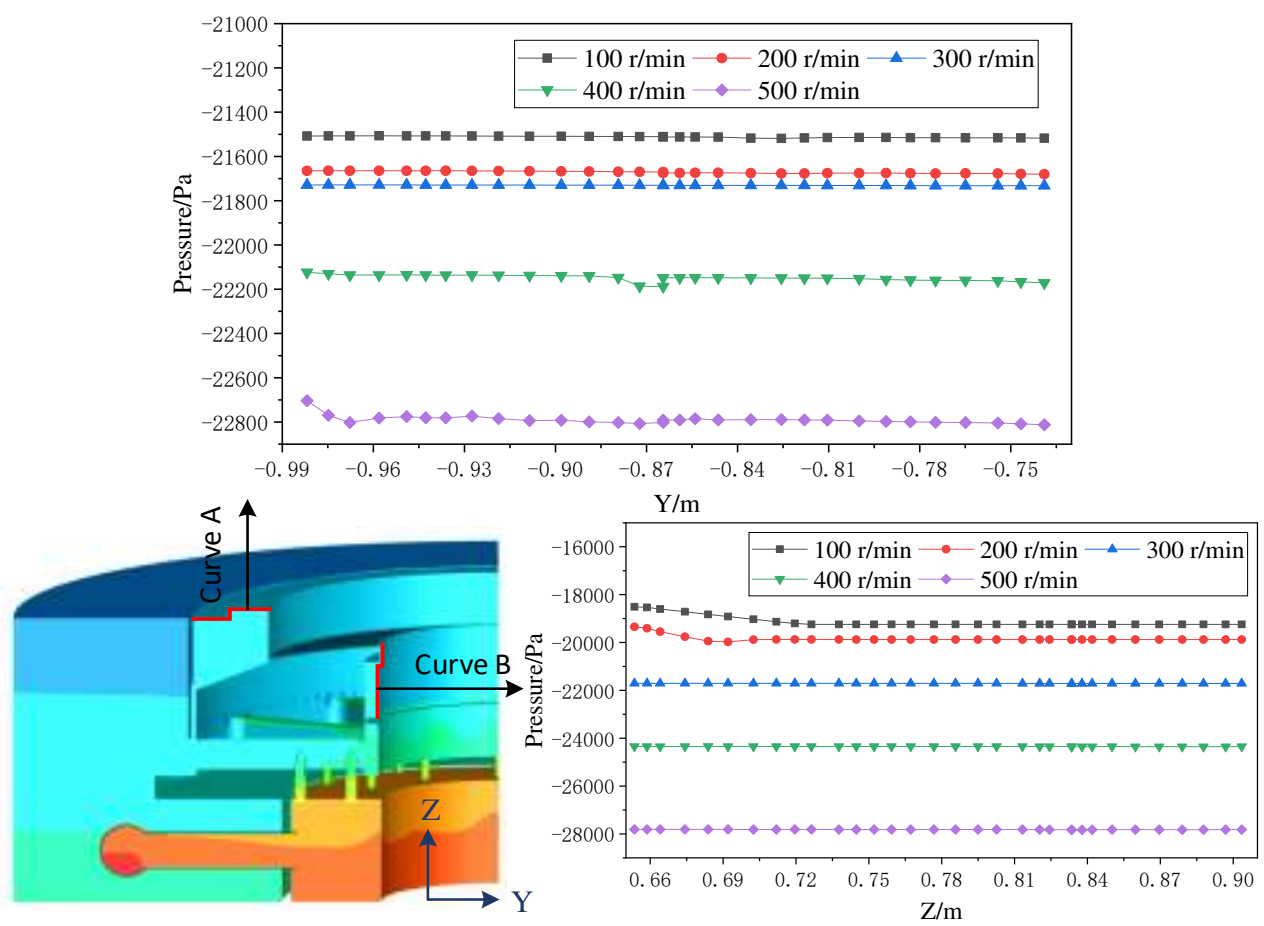
Fig. 16 Pressure distribution diagrams on curves A and B at different speeds

\subsubsection{Effect of speed change on tank temperature}

During operation, the heat generated around the thrust-bearing pad tends to rise to the outer tank cover and extend first to the inner tank and then to the oil slinger region. This effect, demonstrated in Fig. 17, is more pronounced with speed. By contrast, the temperature of region B is almost constant with rotational speed due to the cooling work.
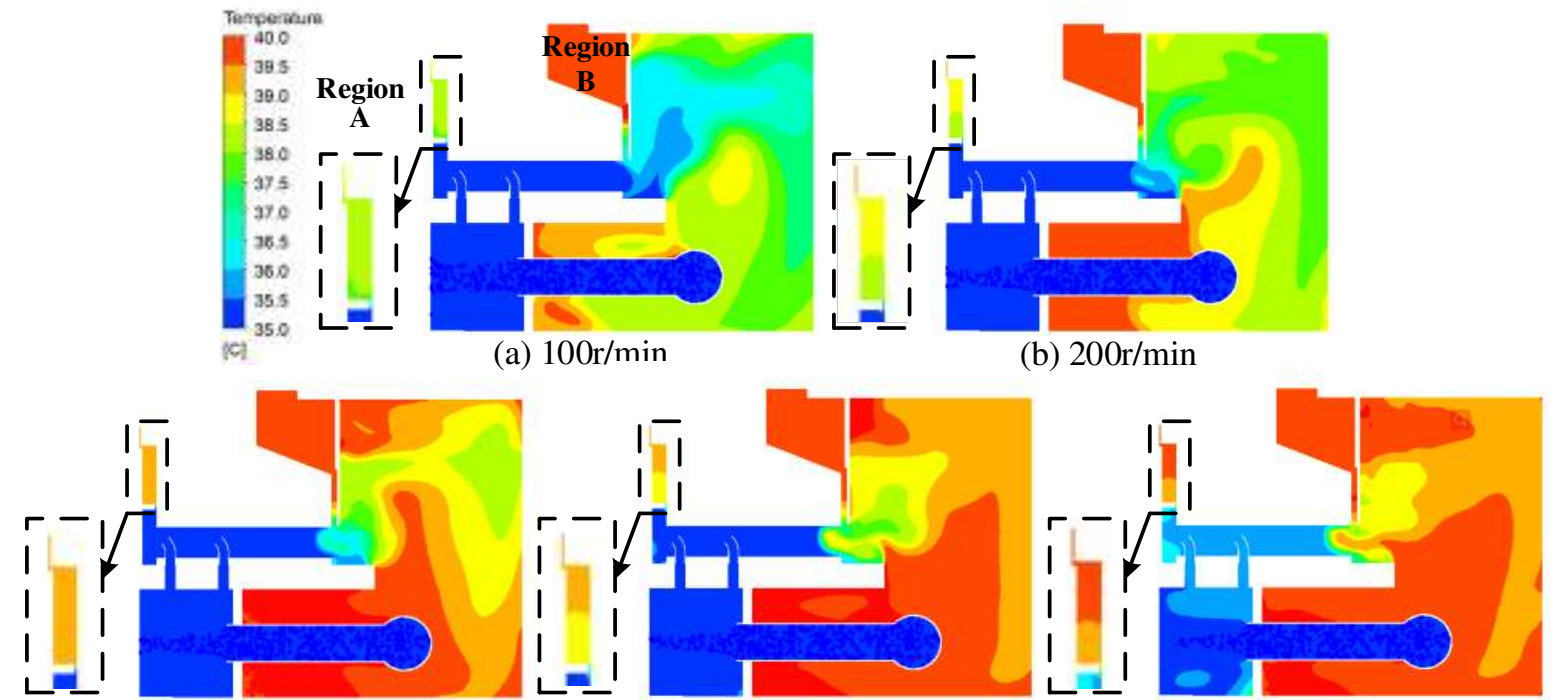

(c) $300 \mathrm{r} / \mathrm{min}$

(d) $400 \mathrm{r} / \mathrm{min}$

(e) $500 \mathrm{r} / \mathrm{min}$

Fig. 17 temperature cloud diagram on rotating periodic boundary surface at different speeds

To obtain details around the oil slinger, the temperatures of the upper and lower regions of the deflected (oil) zone with speed are plotted in Fig. 18. The temperature curve for the lower region remain somewhat constant and increase with speed $\left(35^{\circ}\right.$ to $\left.36.5^{\circ}\right)$. A similar trend is observed with the upper region but at higher initial temperature values. The difference between maximum and minimum temperature with the maximum speed case is $1.3{ }^{\circ} \mathrm{C}$. Increasing the temperature in the region A will increase the thermal movement and intensify the oil turbulence. With the addition of the enormous centrifugal force brought by the increase of rotational speed, the probability of oil leaks rises.

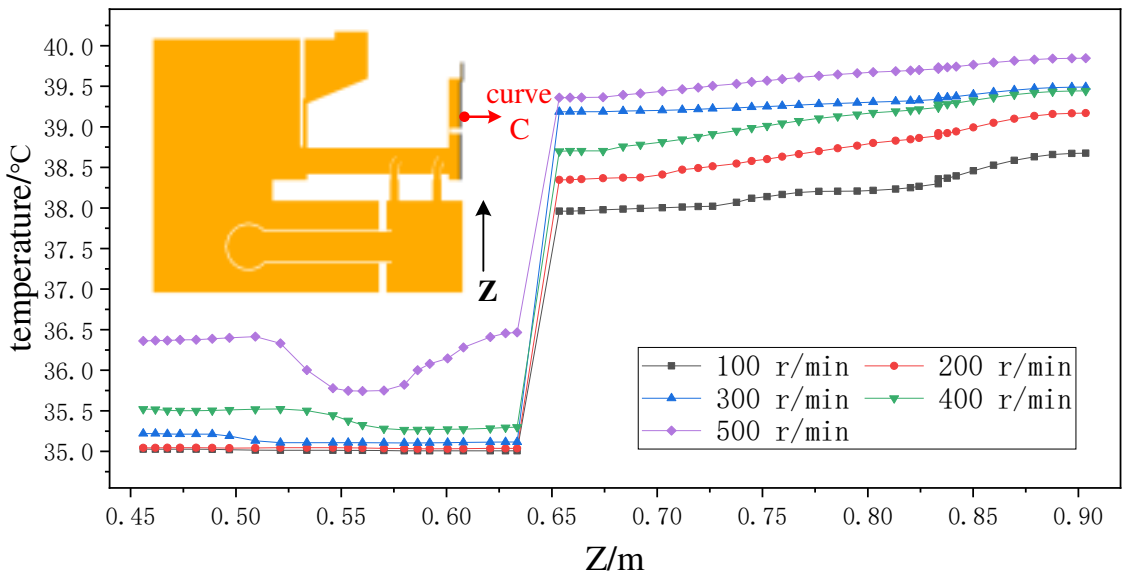

Fig. 18 Temperature change on curve $\mathrm{C}$

\subsubsection{Effect of rotational speed on the flow velocity of the oil tank}

The effect of the rotational speed on the velocity field of the oil tank is analyzed in the regions A and B (see Fig. 19). Clearly, the velocity is induced from the cold pipe to the injection section, and then to the oil slinger and inner tank regions. With rotational speed augmentation, some of the velocity field from the 
inner tank, and all of the injection and cold pipe's tend toward the oil slinger.

Importantly, the higher the rotational speed, the higher the kinetic energy of the oil mist and of collisions with rotating parts. Several splashing oil droplets can thus be formed, prompting oil mist leaks. For this reason, Fig. 20 shows the velocity around the circumference of the rotating part (the thrust head and mirror plate). As observed, The greater the rotational speed, the greater the circumference velocity difference of rotating parts. When the speed is $100 \mathrm{r} / \mathrm{min}$, the maximum circumferential velocity difference is $5 \mathrm{~m} / \mathrm{s}$. When the speed is $500 \mathrm{r} / \mathrm{min}$, the maximum circumferential velocity difference can reach $30 \mathrm{~m} / \mathrm{s}$. This will aggravate the stirring of lubricating oil in the flow field of the oil tank, the splashing of oil and the production of oil foam.

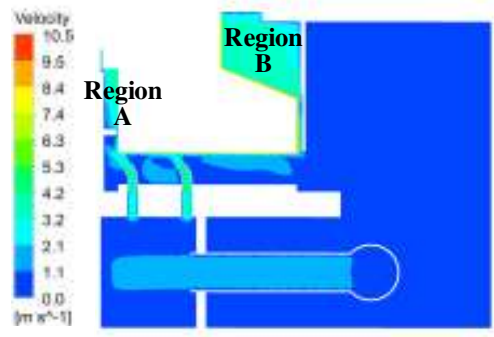

(a) $100 \mathrm{r} / \mathrm{min}$

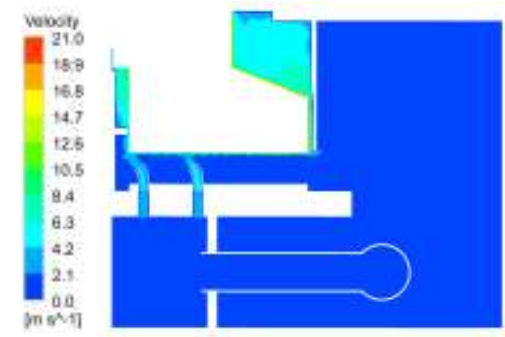

(b) $200 \mathrm{r} / \mathrm{min}$

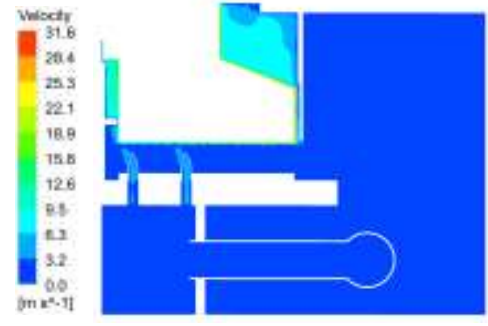

(c) $300 \mathrm{r} / \mathrm{min}$

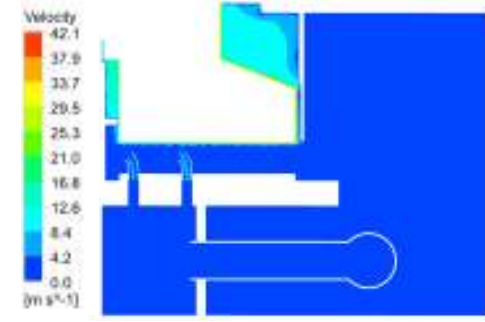

(d) $400 \mathrm{r} / \mathrm{min}$

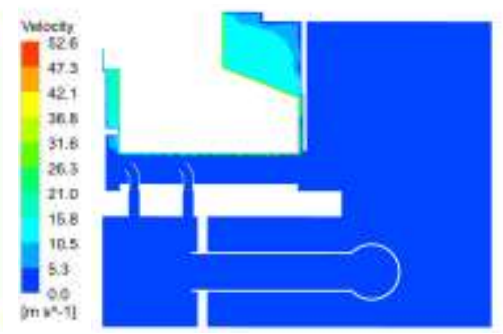

(e) $500 \mathrm{r} / \mathrm{min}$

Fig. 19 velocity distribution diagram of the periodic boundary surface at different speeds

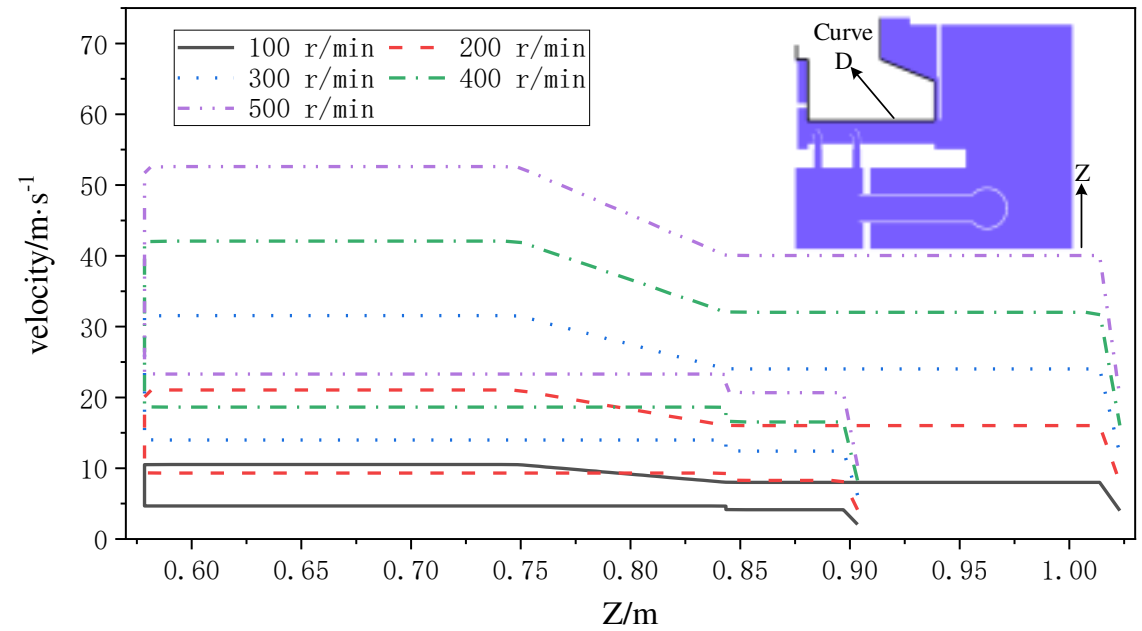

Fig. 20 velocity change diagram on the circumference of the rotating part

\section{Conclusion}

The primary aim of the paper was to explore the relationship of oil mist leakage in the thrust bearings with respect to bearing pad temperature and unit rotational speed. A real case numerical approach was used to assess the lubrication oil path, a useful step for the management of anti oil-throwing practices. The findings suggest the oil mist formation and accumulations grow with temperature, regardless of the pump 
rotational speed, into two zones: between the thrust head and the oil-retaining ring, causing external leaks; the oil slinger, causing internal leaks.

In summary, the increase of velocity and temperature will aggravate the formation of oil mist. Firstly, the increase of speed reduces significantly the pressure around the oil-slinger but moderately around the inner and outer tank, thereby the probability of occurrence is higher for internal than external leak. Secondly the speed and heat generated by the thrust bearing per unit time are sequenced, diminishing the cooling performance. The high temperature, along with the centrifugal force, rise the occurrence of oil leaks. During the studied conditions (temperature range: $56{ }^{\circ} \mathrm{C}-62{ }^{\circ} \mathrm{C}$; rotating speed range: $\mathrm{n}=100-500$ $\mathrm{r} / \mathrm{min}$ ), the oil slinger action prevented leaks. Whilst, the external leaks were dependent on the sealing quality of the oil tank cover.

The study was limited in two ways: First, the arbitrariness of the oil level: obtained during shutdown rather than operation. Second, the steady flow calculation, therefore, future work should establish the susceptibility of oil leakage during transitory state, such as start-up, shut down, and runaway. More studies regarding the role of unit speed in thermal fatigue and cooling efficiency would be worthwhile, in order to assess the lifespan of the system components.

\section{Funding}

This work was supported by the National Natural Science Foundation of China (Grant No. 51579080). State Grid Xinyuan Holding Co., Ltd Technology Project (SGXYKJ-2021-037)

\section{Declaration of competing interest}

The authors declare that they have no known competing financial interests or personal relationships that could have appeared to influence the work reported in this paper.

\section{Acknowledgments}

Thanks for the thrust bearing model data provided by the Hongping Pumping storage Power Station.

\section{Reference}

[1] Yuan Bo, Zhang Lei, Wang Weiping. Oil Vapor Treatment of Vertical Hydro-generator Bearing [J]. Hydropower Automation and Dam Monitoring, 2015, 1(3): 43-48.

[2] Jang G Jung K, Kim J. Behavior of fluid lubricant and air-oil interface of operating FDBs due to operating condition and seal design[J]. Microsystem technologies, 2012, 18(9-10): 1373-1381.

[3] Ashour N M. An investigation on large thrust bearings[C]/Proceedings of the 13th international conference on aerospace sciences \& aviation technology. 2009, Cairo,Egypt,

[4] Plante P, Soule E D, Energy F P L, et al. Thrust Bearing Retrofit: A Case Study of the Cataract Generating Station[J]. hydro tech: 1-9.

[5] Yu Feng. Fault analysis of oil-throwing ring of hydraulic guide bearing in Caijiazhou Hydropower Station [J]. Mechanical and Electrical Information, 2021, 4(11): 27-28 (In Chinese).

[6] Lan Ruile, Wei Haibin, Wu Feng. Causes and Control Measures of Dust and Oil Mist from Generators in Yantan Hydropower Station [J]. Hongshui River, 2016, 35(6): 96-97+102 (In Chinese).

[7] Liu Jie, Deng Guoqi. Oil Splashing Treatment for Thrust Bearing of The No. 2 Unit at Dafa Hydropower Station on Tianwanhe River [J]. SICHUAN WATER POWER, 2010, 29(2): 120-122 (In Chinese).

[8] Luo Yunjun. Remedial Treatment of Oil Leek from Thrust Bearing Oil Retaining Tube in Xiaolangdi Hydroelectric Power Station [J]. DESIGN OF HYDROELECTRIC POWER STATION, 2003, 4(3): 
86-89+96 (In Chinese).

[9] Mahesh A Sahoo S, Panigrahi A. Impact of contamination by bamboo decomposition and lubricant oil leak and deterioration of Balimela reservoir water standard at Malkangiri of Odisha[J]. Natural Journal of Life Science, 2014, 11(2): 01-06.

[10] Hrabovský J Novotný P, Juračka J, et al. Effective thrust bearing model for simulations of transient rotor dynamics[J]. International journal of mechanical sciences, 2019, 157: 374-383.

[11] Rotta G Wasilczuk M. On the possibilities of decreasing power loss in large tilting pad thrust bearings[J]. International Scholarly Research Notices, 2013, 2013: 1-9.

[12] Untaroiu A. Fu G. An optimum design approach for textured thrust bearing with elliptical-shape dimples using computational fluid dynamics and design of experiments including cavitation[J]. Journal of Engineering for Gas Turbines and Power, 2017, 139(9): 092502.

[13] Zhang S, Jiang S, Lin X. Static and dynamic characteristics of high-speed water-lubricated spiral-groove thrust bearing considering cavitating and centrifugal effects[J]. Tribology International, 2020, 145: 106159.

[14] Hargreaves D J. J De Pellegrin D V. An isoviscous, isothermal model investigating the influence of hydrostatic recesses on a spring-supported tilting pad thrust bearing[J]. Tribology international, 2012, 51: 25-35.

[15] Pang Jiayang, Liu Xiaonbing, Ren Minghui, et al. Analysis on the Causes of Oil Mist in the Lower Guide Bearings of Hydrogenerator Units [J/OL]. Journal of Engineering for Themal Energy and Power, 1-7[2021-07-12].http://kns.cnki.net/kcms/detail/23.1176.TK.20210630.0856.002.html (In Chinese).

[16] Chen Zhu, Yu Bo, Zhang Hongqu. Pressure Distribution of Hydraulic Turbine Guide Bearing Rotating Sump[J]. Large Electric Machine And Hydraulic Turbine, 2010, 2: 57-60 (In Chinese).

[17] Deng Y, Xu J, Yang L, et al. Numerical simulation and experimental research on oil mist overflowing for a giant hydropower generator[J]. Energy Sources, Part A: Recovery, Utilization, and Environmental Effects, 2019, 41(19): 2346-2355.

[18] Lu Deping. Flow-Field Analysis And Structure Optimization Of Oil Sump In Thrust Bearing Of Large-Scale Water Turbine Generator[D]. Harbin Institute of Technology, 2010 (In Chinese).

[19] Zou Linfeng, Tang chi, Gu xiangwu, et al. Comparative analysis of external circulation cooling methods of thrust bearing in a large hydropower plant[J]. Mechanical \& Electrical Technique of Hydropower Station, 2020, 43(3): 4-6+13+71(In Chinese).

[20] Fadhl B, Wrobel L C, Jouhara H. Numerical modelling of the temperature distribution in a two-phase closed thermosyphon[J]. Applied Thermal Engineering, 2013, 60(1-2): 122-131.

[21] Shi Xiaojun, Wang Yingzhao, Chen Gangqing, et al. Numerical Simulation of Flow And Heat Transfer of Heat Pipe Used for Stator Cooling of Motorized Spindle [J/OL]. Journal of Xi'an Jiaotong University, 2021, (10): 1-8 [2021-07-28]. http://kns.cnki.net/kcms/detail/61.1069.t.20210601.1139.004.html (In Chinese).

[22] Zhang Chengzhi. Size optimization of thrust bearing oil groove of hydro-generator unit based on CFD [D], Changchun Institute of Technology , 2020 (In Chinese).

[23] Zhang Yun. CFD Analysis on Evaporation during Refueling [D]. JIANGSU university, 2017 (In Chinese).

[24] Hu Zhaochen. Research On Two-Phase Flow Characteristics Of Oil-Gas In Aero-Engine Bearing Chamber [D]. SHENYANG Aerospace University, 2020 (In Chinese).

[25] Sun Boyuan. Numerical Simulation of Splash Lubrication Oil Quantity Imbalance between Two Columns of Cylinder in a V-type Diesel Engine [D]. Dalian University of Technology, 2018 (In Chinese).

[26] Lee W H. A pressure iteration scheme for two-phaseflow modeling[M]. Washington, USA: 
HemispherePublishing, 1980.

[27] Zhao Yutong. Research on anti-oil mist escape device of thrust bearing of Mianhuatan Hydropower Station [D]. Changchun Institute of Technology, 2020 (In Chinese).

[28] Calculation report of thrust bearing for Hongping pumped storage power station[R]. 2013.

[29] Ou Shi, Feng Jiwei. Analysis and Solution of Bearing Oil Dumping in Chongqing Jiangkou Hydropower Station No.3 Unit[J]. Mechanical Engineer, 2020, 4(10): 122-123+127 (In Chinese).

[30] Liu Qi. Failure and treatment of generator oil dump [J]. HEILONGJIANG SCIENCE, 2014, 5(2): 187 (In Chinese). 